\title{
Pituitary deficiency following aneurysmal subarachnoid haemorrhage
}

\author{
I Kreitschmann-Andermahr, C Hoff, S Niggemeier, S Pruemper, M Bruegmann, \\ D Kunz, S Matern, J M Gilsbach
}

\begin{abstract}
Objective: To investigate the incidence and severity of pituitary insufficiency after aneurysmal subarachnoid haemorrhage.

Methods: Pituitary function was tested in a series of patients more than 12 months but less than 60 months after aneurysmal subarachnoid haemorrhage using a combined TRH-LHRH-arginine test and the insulin tolerance test, to elucidate possible deficits in the gonadotrophic, somatotrophic, thyreotrophic, and corticotrophic hormonal axes.

Results: Of 21 patients screened, nine (43\%) showed deficiencies of at least one pituitary hormone axis. Four patients had corticotrophin deficiency, one had partial growth hormone deficiency, two had severe growth hormone deficiency, and two had severe growth hormone deficiency plus corticotrophin deficiency.

Conclusions: Persistent pituitary dysfunction may be more common after aneurysmal subarachnoid haemorrhage than has so far been recognised and warrants further investigation, given the possibility that some health and neurobehavioural problems in these patients could result from hormone deficiency.
\end{abstract}

$\mathrm{P}$ atients in the chronic stage of aneurysmal subarachnoid haemorrhage - that is, more than one year after the acute event-still report subjective complaints such as a diminished level of performance, increased irritability, loss of initiative, and cognitive deficits. ${ }^{1}$ These impairments are encountered even then when the neurological late results, as measured by the Glasgow outcome scale, ${ }^{2}$ are good and no substantial brain damage can be shown on computed tomography (CT) or magnetic resonance imaging. ${ }^{1}$ There are striking parallels in the subjective descriptions of complaints and the objective deficits between patients after subarachnoid haemorrhage and those with untreated partial or complete pituitary insufficiency involving the adrenocortical, gonadal, thyroid hormone, or growth hormone axes. ${ }^{34}$

Apart from an investigation of post-traumatic hypopituitarism which included two patients after aneurysmal subarachnoid haemorrhage, ${ }^{5}$ the long term effects of subarachnoid haemorrhage on pituitary function have not been assessed. It was, therefore, our aim in this study to investigate the incidence and severity of pituitary insufficiency in patients more than one year after aneurysmal subarachnoid haemorrhage.

\section{METHODS}

Clinical details of the patients

Subjects were recruited from a consecutive series of 128 patients who had sustained aneurysmal subarachnoid haemorrhage and were operated on in the department of neurosurgery, University Hospital Aachen, between December 1998 and
May 2001. Eligibility criteria included a time window of subarachnoid haemorrhage of more than 12 months but less than 60 months before pituitary function testing, age between 18 and 60 years at the time of testing, and no history of convulsions or adequate anticonvulsive treatment followed by a six month convulsion-free period. Exclusion criteria included severe liver, heart, and kidney disease and diabetes mellitus, as well as severe depression. In cases of current treatment with thyroid hormones or oestrogens, treatment was discontinued before pituitary function testing.

The study design was approved by the ethics committee of the University Hospital Aachen. Of the 128 patients, 53 were older than 60 years, 11 had moved to an unknown address, 16 had a poor neurological result and were considered unable go give informed consent, eight were excluded for medical reasons, and one patient had died. Of the remaining 39 patients invited to take part in the study, 13 did not want to participate for personal reasons. Of the remaining 26 patients who initially consented to take part in the investigation, five withdrew their consent before pituitary testing $(n=3)$ or did not complete both tests $(n=2)$. The reported interim results are therefore based on the 21 patients (eight male, 13 female) who completed dynamic pituitary testing.

Patients were tested between 14 and 43 months after the subarachnoid haemorrhage (mean (SD), 24.6 (9.5) months). Mean age at the time of subarachnoid haemorrhage was 42 (7) years, range 28 to 56 . Mean clinical grade on admission to hospital, using the Hunt and Hess grading system, ${ }^{6}$ was 2.5 (1.2), with a range from 1 (mild headache) to 5 (coma). The mean severity of the bleeding seen on cranial CT was 2.5 (0.7) according to the classification of Fisher et al, ${ }^{7}$ ranging from no blood present (grade 0) to severe, extended, diffuse subarachnoid haemorrhage (grade 3). The aneurysms in the investigated patients were treated by microneurosurgical clipping in all cases.

Aneurysm locations were as follows: six involved the anterior communicating artery, three the middle cerebral artery, two the internal carotid artery, four the posterior communicating artery, one the pericallosal artery, one the anterior choroidal artery, one the vertebral artery, one the posterior inferior cerebellar artery, and one the posterior cerebral artery. One patient had been operated on for a ruptured posterior communicating artery aneurysm in 1995 and for a symptomatic middle cerebral artery aneurysm in 2001.

In the six month follow up examination, the patients had mainly recovered well according to the Glasgow outcome scale, with six rated as grade $\mathrm{V}$ (no or minimal impairment), 11 as grade IV (modest impairment, needing no help with daily life), and only four as grade III (severe impairment, needing help for daily life). The patients reported having gained an average of 6.9 (7.8) $\mathrm{kg}$ in weight after the acute event (range -10 to $20 \mathrm{~kg}$ ). Their mean body mass index (BMI) at the time of pituitary function testing was 27.3 (5.8) $\mathrm{kg} / \mathrm{m}^{2}$ (range 17 to 39 ). The Beck depression inventory, ${ }^{8}$ a self rating inventory, showed that $12(57 \%)$ of the 21 patients were 
Table 1 Characteristics of the patients with pituitary deficiency after subarachnoid haemorrhage

\begin{tabular}{|c|c|c|c|c|c|c|c|c|c|c|c|c|c|c|}
\hline \multicolumn{2}{|c|}{ PatientSex } & \multirow{2}{*}{$\begin{array}{l}\begin{array}{l}\text { Age at } \\
\text { time of } \\
\text { SAH } \\
\text { (years) }\end{array} \\
38\end{array}$} & \multirow{2}{*}{$\begin{array}{l}\mathrm{H} \& \mathrm{H}^{\prime} \\
3\end{array}$} & \multirow{2}{*}{$\begin{array}{l}\text { Severit } \\
\text { of } \\
\mathrm{SAH}^{2}\end{array}$} & \multirow{2}{*}{$\begin{array}{l}\text { Aneurysm location } \\
\text { Middle cerebral }\end{array}$} & \multicolumn{2}{|c|}{$\mathrm{GOS}^{3} \mathrm{BDI}^{4}$} & \multirow{2}{*}{ 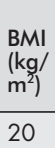 } & \multirow{2}{*}{$\begin{array}{l}\text { Weight } \\
\text { gain } \\
(\mathrm{kg})\end{array}$} & \multicolumn{2}{|c|}{$\begin{array}{c}\text { Max GH } \\
\text { in ITT } \\
\text { Shunt }(\mu \mathrm{g} / \mathrm{I})\end{array}$} & \multirow{2}{*}{ 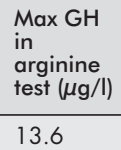 } & \multirow{2}{*}{$\begin{array}{l}\begin{array}{l}\text { Max. } \\
\text { cortisol } \\
\text { in ITT } \\
(\mu \mathrm{g} / \mathrm{I})\end{array} \\
464\end{array}$} & \multirow{2}{*}{$\begin{array}{l}\text { Deficient hormone } \\
\text { axis }\end{array}$} \\
\hline 1 & $\mathrm{~F}$ & & & & & 4 & 11 & & & No & 24.4 & & & \\
\hline 2 & $\mathrm{~F}$ & 44 & 2 & 3 & Pericallosal & 4 & 4 & 25 & 10 & No & 18.7 & 33.2 & 466 & ACTH deficiency \\
\hline 3 & $\mathrm{~F}$ & 49 & 2 & 3 & $\begin{array}{l}\text { Anterior } \\
\text { communicating }\end{array}$ & 4 & 19 & 32 & 17 & No & 1.8 & 2.7 & 514 & Severe GH deficiency \\
\hline 4 & $\mathrm{~F}$ & 45 & 1 & 3 & $\begin{array}{l}\text { Anterior } \\
\text { communicating }\end{array}$ & 4 & 16 & 37 & 20 & Yes & $<0.1$ & 2.1 & 244 & $\begin{array}{l}\text { Severe GH and } \\
\text { ACTH deficiency }\end{array}$ \\
\hline 5 & $M$ & 38 & 2 & 2 & Anterior choroidal & 5 & 4 & 37 & 15 & No & 2.6 & 0.3 & 625 & Severe GH deficiency \\
\hline 6 & $\mathrm{~F}$ & 39 & 1 & 1 & $\begin{array}{l}\text { Posterior } \\
\text { communicating }\end{array}$ & 4 & 11 & 25 & 10 & No & 1.7 & 14.3 & 357 & ACTH deficiency \\
\hline 7 & $\mathrm{~F}$ & 45 & 5 & 3 & MCA ('01); PCoA & 3 & 11 & 25 & 0 & No & 3.3 & 1.4 & 536 & Partial GH deficiency \\
\hline 8 & $\mathrm{~F}$ & 46 & 3 & 2 & $\begin{array}{l}\text { Anterior } \\
\text { communicating }\end{array}$ & 4 & 11 & 26 & 15 & No & 13.9 & 16.2 & 368 & ACTH deficiency \\
\hline 9 & $\mathrm{~F}$ & 54 & 1 & 1 & $\begin{array}{l}\text { Anterior } \\
\text { communicating }\end{array}$ & 5 & 4 & 39 & 7 & No & 1.0 & 2.1 & 444 & $\begin{array}{l}\text { Severe GH and } \\
\text { ACTH deficiency }\end{array}$ \\
\hline
\end{tabular}

'According to the grading system of Hunt and Hess (1968), ranging from mild headache (grade 1) to coma (grade 5).

${ }^{2}$ According to the classification of the severity of subarachnoid haemorrhage seen on cranial computed tomography by Fisher et al (1980), ranging from no blood present (grade 0) to severe, extended diffuse SAH (grade 3).

${ }^{3}$ At six-month follow up, according to the Glasgow outcome scale (Jennett and Bond, 1967), ranging from no/minimal impairment (grade V) to death (grade I).

${ }_{4}^{4}$ According to the Beck depression inventory (Beck 1961): mild depression is indicated by a score of $\geqslant 9$, severe depression by a score of $\geqslant 21$. Note that severe depression was an exclusion criterion from the present study.

ACTH, adrenocorticotrophin; BDI, Beck depression inventory; BMI, body mass index; GH, growth hormone; GOS, Glasgow outcome scale; H\&H, Hunt and Hess grading system; ITT, insulin tolerance test; MCA, middle cerebral artery; PcoA, posterior communicating artery; SAH, subarachnoid haemorrhage.

mildly to moderately depressed, with scores of $\geqslant 9$ (mean 9.7 (5.6), range 1 to 19$)$.

\section{Laboratory tests}

After routine laboratory testing, a combined TRH-LHRHarginine test and an insulin tolerance test were done on two separate days with a minimum of 48 hours between the two tests. Adequate hypoglycaemia was achieved in all insulin tolerance tests. Hormone levels were measured using automated chemiluminescence immunoassays (Nichols Advantage, Nichols, Bad Nauheim, Germany; Centaur, Bayer Diagnostics, Fernwald, Germany). Severe growth hormone deficiency was indicated by a peak growth hormone response of less than 3 $\mu \mathrm{g} / \mathrm{l}$ in both the insulin tolerance test and TRH-LHRH-arginine test (with $30 \mathrm{~g}$ arginine in $\mathrm{NaCl}$ given over 30 minutes); partial growth hormone deficiency was indicated by a peak growth hormone response of between 3 and $5 \mu \mathrm{g} / \mathrm{l}$ in both tests. Adrenocorticotrophin (ACTH) deficiency was diagnosed if peak serum cortisol levels during insulin tolerance test were less than $500 \mathrm{nmol} / \mathrm{l}$. Diagnosis of gonadotrophin deficiency was based on basal and stimulated luteinising hormone (LH) and follicular stimulating hormone (FSH) levels, testosterone concentrations in men, and oestradiol concentrations plus menstrual disturbances in women. Thyreotrophin deficiency was defined as a decreased fT4 (thyroxine) concentration in the presence of inadequately low basal and stimulated thyroid stimulating hormone (TSH) levels

\section{RESULTS}

According to these criteria, four patients were diagnosed as having ACTH deficiency, one as having partial growth hormone deficiency, two as having severe growth hormone deficiency, and two as having severe growth hormone deficiency plus ACTH deficiency. Neither disturbances of gonadotrophin or thyreotrophin secretion nor polydipsia syndrome and electrolyte disturbances were observed in our patients. The clinical characteristics of the patients with hormone deficiencies are listed in table 1.

Patients with severe growth hormone deficiency had gained on average $9.3 \mathrm{~kg}$ more weight after the subarachnoid haemorrhage than patients without growth hormone deficiency and had a higher body mass index (mean BMI, $36.3 \vee 25.0$ $\mathrm{kg} / \mathrm{m}^{2}$ ). Both weight gain after subarachnoid haemorrhage and BMI were significantly associated with severe growth hormone deficiency (Mann-Whitney U test: $p=0.029$ and $p<0.0001$, respectively). Neither partial or severe growth hormone deficiency nor ACTH deficiency were associated with clinical state on admission, severity of the bleeding on CT, neurological outcome (Glasgow outcome scale), time between subarachnoid haemorrhage and pituitary function testing, or self rated depression score (Beck depression inventory).

\section{DISCUSSION}

The results of our study show that pituitary insufficiency after aneursymal subarachnoid haemorrhage may be a more common long term sequel than has so far been recognised. The pathophysiological basis of this decreased hormone secretion remains to be determined. Possible mechanisms include direct hypothalomopituitary damage by the subarachnoid blood, and damage to the hypothalomopituitary axis as a result of intracranial hypertension, a decrease in cerebral perfusion pressure, or cerebral vasospasm following the subarachnoid haemorrhage. Traumatic or ischaemic lesions of the pituitary stalk and hypothalamus following intraoperative manipulation during aneurysm surgery should also be considered as potential causes of hypopituitarism. It is conceivable that aneurysms of the anterior communicating artery predispose to later hormone deficiency, as perforating arteries arising from this vessel supply the lamina terminalis and the anterior hypothalamus.

The concept of a hypothalamic cause for hormone deficiency in subarachnoid haemorrhage may also explain why the usual hierarchy of pituitary insufficiency-with growth hormone deficiency occurring first, followed by FSH/LH deficiency, and then ACTH deficiency-was not observed in our study. In our patients, severe growth hormone deficiency was significantly associated with an increased BMI. It is difficult to distinguish reduced growth hormone secretion associated with obesity from organic growth hormone deficiency. ${ }^{9}$ However, the fact that weight gain after subarachnoid haemorrhage was associated with severe growth hormone deficiency, and the finding that two patients with severe growth hormone deficiency also had ACTH deficiency, lend weight to the view that the reduced growth hormone 
response in the insulin tolerance test was secondary to organic growth hormone deficiency associated with the subarachnoid haemorrhage.

Our results must be regarded as preliminary because the small sample size compromises the interpretation of statistical tests. However, the fact that $43 \%$ of the patients in our small and selected patient sample had partial pituitary insufficiency suggests that endocrine disturbances should be considered a potential cause of impaired quality of life and general health after subarachnoid haemorrhage. Given the possibility that the symptoms in these patients might be alleviated by hormone substitution, further research into this subject is clearly warranted.

\section{Authors' affiliations}

I Kreitschmann-Andermahr, S Niggemeier, S Pruemper, J M

Gilsbach, Department of Neurosurgery, University Hospital, Aachen University, Aachen, Germany

C Hoff, S Matern, Endocrine Outpatient Clinic, Department of Internal Medicine III, University Hospital, Aachen University

M Bruegmann, Department of Medical Psychology and Sociology,

University Hospital, Aachen University

D Kunz, Institute for Clinical Chemistry and Pathobiochemistry, University Hospital, Aachen University

Competing interests: IK-A and $\mathrm{CH}$ have been reimbursed by Pharmacia, a manufacturer of growth hormone, for attendance at several conferences held by Pharmacia. IK-A has received fees for speaking. SN's clinical post was paid for in part by money donated to the University Hospital Aachen by Pharmacia to carry out the present study.

Correspondence to: Dr med Ilonka Kreitschmann-Andermahr, University Hospital Aachen, DepartmU

\section{REFERENCES}

1 Hütter BO. Neuropsychological sequelae of subarachnoid hemorrhage and its treatment. Vienna: Springer Verlag, 2000.

2 Jennett B, Bond M. Assessment of outcome after severe brain damage. A practical scale. Lancet 1967;23:878-81.

3 Vance ML. Hypopituitarism. N Engl J Med 1994;330:1651-62.

4 Deijen JB, de Boer $\mathrm{H}$, Blok $\mathrm{GJ}$, et al. Cognitive impairments and mood disturbances in growth hormone deficient men.

Psychoneuroendocrinology 1996;21:313-22.

5 Kelly DF, Gaw Gonzalo IT, Cohan P, et al. Hypopituitarism following traumatic brain injury and aneurysmal subarachnoid hemorrhage: a preliminary report. J Neurosurg 2000:93:743-52.

6 Hunt WE, Hess RM. Surgical risk is related to time of intervention in the repair of intracranial aneurysms. J Neurosurg 1968;28:14-20.

7 Fisher CM, Kistler JP, Davis JM. Relation of cerebral vasospasm to subarachnoid hemorrhage visualized by computerized tomographic scanning. Neurosurgery 1980;6:1-9.

8 Beck AT, Ward CH, Mendelson M, et al. An inventory for measuring depression. Arch Gen Psychiatry 1961;4:561-71.

9 Shalet SM, Toogood A, Rahim A, et al. The diagnosis of growth hormone deficiency in children and adults. Endocrine Rev 1998:19:203-23.

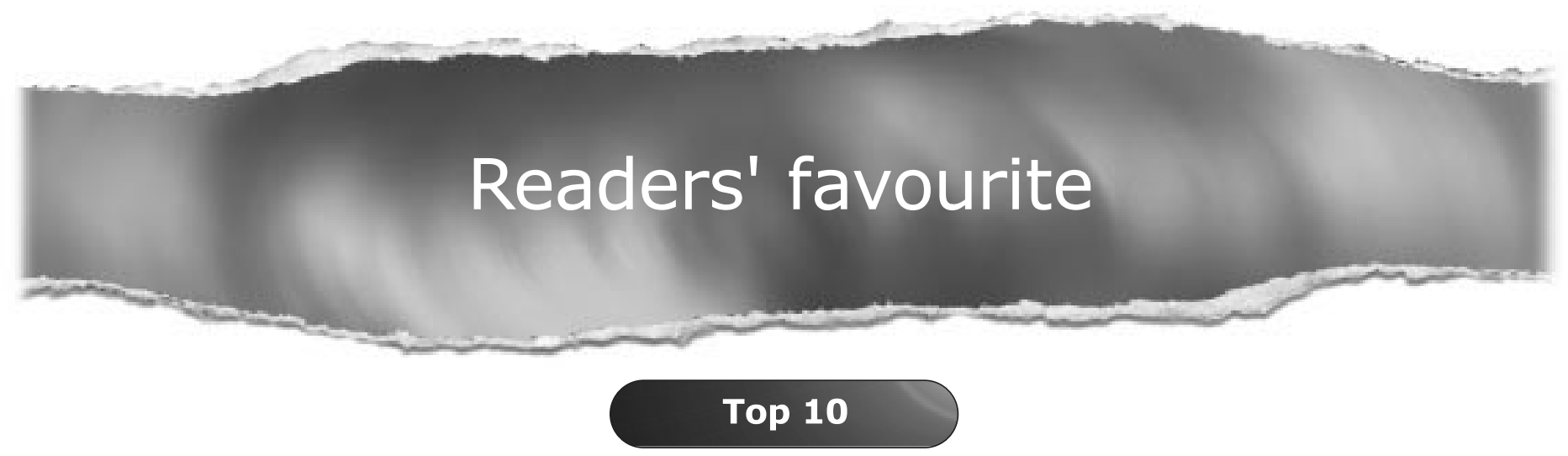

Click on the "Top 10" button on the homepage to see which are the best read articles each month

www.jnnp.com 